\title{
FINGER PAINTING DAN PERKEMBANGAN MOTORIK HALUS PADA ANAK PRASEKOLAH
}

\author{
Wida Putri Hayuningtyas ${ }^{*}$, Hesty Widyasih, Margono \\ Politeknik Kesehatan Kementrian Kesehatan Yogyakarta \\ whayuningtyas@gmail.com
}

\begin{abstract}
ABSTRAK
Perkembangan motorik halus merupakan kemampuan anak untuk mengamati sesuatu dan melakukan gerakan dengan bantuan otot kecil. Kemampuan motorik halus pada anak dapat dikembangkan dengan memberikan stimulasi berupa bermain puzzle, memotong, menggambar, menulis, finger painting dan lain sebagainya. Kurangnya stimulasi akan mengakibatkan anak memiliki gangguan konsentrasi pada saat anak duduk disekolah dasar yang berdampak pada perkembangan kognitif anak. Tujuan : Diketahui pengaruh finger painting terhadap perkembangan motorik halus anak usia prasekolah di PAUD Al Hijrah dan PAUD Smart Sidoluhur, Kecamatan Godean, Sleman. Quasi eksperimental research method with non equivalent control group design. Populasi studi penelitian adalah siswa PAUD Al-Hijrah dan Smart Desa Sidoluhur Kec. Godean dengan sampel masing-masing kelompok 16. Analisis data menggunakan Independent T-Test. Kelompok eksperimen diberikan stimulasi finger painting dan kelompok kontrol diberikan stimulasi menyusun puzzle. Rata-rata perkembangan motorik halus setelah diberikan intervensi mengalami peningkatan baik jenis stimulasi finger painting (sig. 0,000) maupun menyusun puzzle (sig. 0,002). Finger painting lebih meningkatkan perkembangan motorik halus anak pada usia prasekolah dibandingkan dengan menyusun puzzle dengan perbedaan rata-rata nilai selisih 1,000 (sig. 0,007). Kesimpulan : Ada pengaruh finger painting dengan perkembangan motorik halus anak pada usia prasekolah
\end{abstract}

Kata kunci: Finger painting,perkembangan motorik halus, Puzzle

\section{ABSTRACT}

The development of fine motors is a child's ability to observe something and to do muscular movements. The ability of fine motors on children can be developed by giving simulations such as arranging puzzles, cutting, drawing, writing, finger painting, and so on. Lacks of simulations can cause children to have interferences in concentrating when the child has been in a primary school that will lead to cognitive problems. The Purpose of this study was to recognize the influences of finger paintings towards the developments of preschoolers' fine motors in the Pre-Kindergartens of Al Hijrah and Smart Sidoluhur, Godean district, Sleman. This study uses the Quasi Experimental with Non Equivalent Control Group Design method. The populations of the study are the preschoolers of Al Hijrah and Smart Pre-Kindergartens Sidoluhur village, Godean district in which the samples each consists of 16 preschoolers. The data are analyzed by using the Independent T-Test. The experimental group was given the finger painting simulations and the controlling group was given the puzzle simulations. The Results: Evenly the developments of the fine motors, after they were given interventions, increase both in the finger painting simulations (sig 0.000) and 
the puzzle simulations (sig 0.002). The finger paintings increase the developments of fine motors towards preschoolers more than the puzzle simulations with the total different score 1.000 (sig 0.007). Conclusions: There is some influences of finger paintings towards the developments of preschoolers' fine motors.

Keywords: Fine Motor Development, Finger Painting, Puzzle

\section{PENDAHULUAN}

Menurut UNICEF,2012 di Indonesia 40\% balita dipedesaan mengalami pertumbuhan dan perkembangan yang terhambat(Kemenkes, 2017). WHO melaporkan bahwa 5-25\% dari anak-anak usia prasekolah menderita disfungsi otak minor, termasuk gangguan perkembangan. Menurut UNICEF,2011 didapatkan data masih tingginya angka kejadian gangguan pertumbuhan dan perkembangan pada anak balita khususnya gangguan perkembangan motorik didapatkan $(27,5 \%)$ atau 3 juta anak mengalami gangguan(Wayan, Asthiningsih, \& Muflihatin, 2018). Hasil Riset Kesehatan Dasar (Riskesdas) tahun 2018 Indeks perkembangan anak usia 36-59 bulan untuk aspek literasi sebesar 64,6\%, aspek fisik sebesar 97,8\%, aspek sosial emosional sebesar 69,9\%, dan aspek learning sebesar 95,2\% sehingga total indeks perkembangan Indonesia tahun 2018 sebesar $88,3 \%($ RI, 2018).

Gangguan perkembangan yang dialami pada anak dapat berdampak buruk untuk masa depan anak. Anak yang mengalami gangguan motorik dapat terlambat memperoleh keterampilan yang seharusnya dapat dicapai sesuai usianya. Demikian pula anak yang mengalami keterlambatan perkembangan bicara dapat menimbulkan dampak tingkat intelegensi yang rendah serta rendahnya kemampuan bayi untuk bersosialisasi dengan sekitarnya(Hurlock, 2013). Menurut Puri Aquarisnawati, dkk kurangnya stimulasi atau kegiatan yang bersifat fisik khususnya motorik halus halus di TK akan mengakibatkan anak memiliki gangguan konsentrasi pada saat anak telah duduk disekolah dasar yang diakibatkan karena motorik halus anak belum matang dan pada kenyataannya apabila perkembangan motorik halus dapat dilalui dengan baik, maka akan berdampak pada perkembangan kognitif anak, misal anak bisa membaca dengan baik, menulis dengan baik, dan memiliki konsentrasi dengan baik(Aquarisnawati, Mustami'ah, \& Riskasari, 2011).

Untuk mengembangkan kemampuan anak dalam motorik halus sekaligus menanggulangi rasa bosan pada anak, dapat diberikan stimulasi berupa kegiatan yang menarik agar anak dapat mengikuti kegiatan dan belajar dengan baik. Kegiatan yang dapat dilakukan diantaranya bermain puzzle, memotong, membuat cerita gambar tempel, menjahit, menggambar, menulis, menghitung, membuat gambar tempel, mencampur warna, menggambar dengan jari (finger painting) dan lain sebagainya(Sulistyawati, 2014). Berdasarkan data dari Puskesmas Godean 1 Kabupaten Sleman tahun 2018 terdapat 16 PAUD di wilayah kerja puskesmas Godean 1 dan pihak puskesmas menyarankan PAUD Al-Hijrah dan PAUD Smart untuk dilakukan penelitian karena memiliki karakteristik sama dan berdekatan antar PAUD. Peneliti melakukan observasi pada dua PAUD tersebut berdasarkan hasil wawancara kepala sekolah dan wali kelas pada kelompok eksperimen belum pernah melakukan stimulasi finger painting dalam kegiatan pembelajaran di PAUD tersebut untuk meningkatkan perkembangan motorik halusnya. Sedangkan pada kelompok kontrol berdasarkan observasi dalam kegiatan pembelajaran 50\% anak belum dapat memegang pensil dengan benar, kegiatan yang sering dilakukan untuk meningkatkan motorik halus berupa menempel gambar, menggunting pola yang sudah tersedia dan sesekali menyusun puzzle(Puskemas Godean I, 2018). 


\section{METODOLOGI PENELITIAN}

Penelitian ini merupakan penelitian kuasi eksperimen dengan Non Equivalent Control Group Design. Populasi dalam penelitian ini adalah Siswa PAUD Al Hijrah dan PAUD Smart di Desa Sidoluhur Kecamatan Godean Kabupaten Sleman dengan menggunakan kriteria inklusi dan eksklusi. Penelitian ini menggunakan teknik pengambilan sampel purposive sampling yang didasarkan pada suatu pertimbangan tertentu yang dibuat oleh peneliti sendiri berdasarkan ciri atau sifat-sifat populasi yang sudah diketahui sebelumnya(Notoatmodjo, 2012). Penelitian ini menggunakan rumus sampel sederhana dari Alimul Aziz Hidayat dengan hasil $r \geq 16$, Jadi sampel yang digunakan yaitu 16 siswa kelompok eksperimen dengan pemberian perlakuan berupa stimulasi finger painting dan 16 siswa kelompok kontrol dengan pemberian perlakuan berupa stimulasi menyusun puzzle. Penelitian ini dilakukan di PAUD Al Hijrah dan PAUD Smart di Desa Sidoluhur Kecamatan Godean Kabupaten Sleman yang dilaksanakan pada tanggal 7 September 2018 s.d 27 Mei 2019. Instrumen penelitian yang digunakan adalah DDST II, dengan menggunakan alat bantu pemeriksaan tumbuh kembang yaitu kertas HVS, pensil, APE balok, dan manik-manik. Analisis data dalam penelitian ini dilakukan secara univariat dan bivariat. Analisis univariat dengan menggunakan uji chi square dan analisis bivariat menggunakan Paired T Test dilanjutkan dengan Independent T-Test. Penelitian ini telah melalui uji validity content dan telah disetujui oleh komisi etik dari Komisi Etik Politeknik Kesehatan Kemenkes Yogyakarta No. LB.01.01/KE-01/VII/253/2019 pada tanggal 5 Maret 2019.

\section{HASIL DAN PEMBAHASAN}

1. Karakterisitik Subyek

Subyek dalam penelitian ini adalah anak usia prasekolah yang terdaftar dalam PAUD AlHijrah dan PAUD Smart Desa Sidoluhur Kecamatan Godean tahun 2019 sejumlah 16 siswa PAUD Al-Hijrah dan 16 siswa PAUD Smart untuk subyek penelitian dengan perbandingan sebagai berikut :

Tabel. 1 Perbandingan Karakteristik Subyek Kelompok Eksperimen dan Kelompok Kontrol

Kelompok Subyek

\begin{tabular}{|c|c|c|c|c|c|}
\hline \multirow[t]{2}{*}{ Variabel } & \multicolumn{2}{|c|}{ Eksperimen } & \multicolumn{2}{|c|}{ Kontrol } & \multirow[t]{2}{*}{$P$ Value } \\
\hline & $\mathbf{N}$ & $\%$ & $\mathbf{N}$ & $\%$ & \\
\hline \multicolumn{6}{|l|}{ Jenis Kelamin } \\
\hline a. Laki-laki & 9 & $56,25 \%$ & 9 & $56,25 \%$ & \multirow[t]{2}{*}{1,000} \\
\hline b. Perempuan & 7 & $43,75 \%$ & 7 & $43,75 \%$ & \\
\hline \multicolumn{6}{|l|}{ Pendidikan ibu } \\
\hline a. Dasar & 4 & $25 \%$ & 3 & $18,75 \%$ & \multirow[t]{3}{*}{0,453} \\
\hline b. Menengah & 9 & $56,25 \%$ & 6 & $37,50 \%$ & \\
\hline c. Tinggi & 3 & $18,75 \%$ & 7 & $43,75 \%$ & \\
\hline \multicolumn{6}{|l|}{ Pendidikan Ayah } \\
\hline a. Dasar & 5 & 31,25 & 4 & $25 \%$ & \multirow[t]{3}{*}{0,645} \\
\hline b. Menengah & 7 & $43,75 \%$ & 6 & $37,50 \%$ & \\
\hline c. Tinggi & 4 & $25 \%$ & 6 & $37,50 \%$ & \\
\hline \multicolumn{6}{|l|}{ Penghasilan Keluarga } \\
\hline a. $\quad<\operatorname{Rp} 1.701 .000$ & 6 & $37,50 \%$ & 6 & $37,50 \%$ & \multirow[t]{2}{*}{1,000} \\
\hline b. $\quad \geq \operatorname{Rp} 1.701 .000$ & 10 & $62,50 \%$ & 10 & $62,50 \%$ & \\
\hline
\end{tabular}


Berdasarkan tabel 1, dapat diketahui bahwa proporsi subyek yang berjenis kelamin laki-laki pada kelompok eksperimen tidak berbeda bermakna dibanding dengan kelompok kontrol $(56,25 \%$ vs $56,25 \%)$ p value 1,000 , proporsi ibu subyek yang berpendidikan dasar pada kelompok eksperimen juga tidak berbeda bermakna dibanding dengan kelompok kontrol (25\% vs $18,75 \%) p$ value 0,453 . Proporsi ayah subyek yang berpendidikan dasar pada kelompok eksperimen juga tidak berbeda bermakna dengan kelompok kontrol (31,25\% vs $25 \%), p$ value 0,645 , demikian pula proporsi orang tua (keluarga) dari subyek yang berpenghasilan kurang dari Rp.1.701.000,- (UMR) pada kelompok eksperimen tidak berbeda bermakna dibanding dengan kelompok kontrol (37,50\% vs 37,50\%) p value 1,000, dengan demikian dalam hal 4 karakteristik yaitu jenis kelamin, tingkat pendidikan ibu, tingkat pendidikan ayah dan penghasilan keluarga dari kedua kelompok subyek adalah sama atau homogen

2. Analisis Bivariat

Sebelum dilakukan analisis data dengan menggunakan statistik parametrik, dalam penelitian ini adalah $t$-test maka dilakukan uji normalitas untuk mengetaui apakah data-data sampel yang diperoleh dalam penelitian ini berdistribusi normal atau tidak. Uji normalitas dalam penelitian ini diperoleh sesudah diberi perlakuan menggunakan uji One-Sample Kolmogorov-Smirnov dengan software komputer. Hasil perhitungan uji normalitas p-value 0,417. Dari hasil perhitungan uji normalitas menunjukkan bahwa $p$-value $>0,05$ sehingga dapat diketahui data tersebut berdistribusi normal, sehingga analisis data-data penelitian ini dilakukan secara parametrik menggunakan $t$-test.

Analisis dilakukan untuk menguji Pengaruh finger painting terhadap peningkatan perkembangan motorik halus anak usia prasekolah di PAUD Al-Hijrah dan PAUD Smart Desa Sidoluhur Kecamatan Godean dilakukan 3 tahap yaitu:

a. Analisis perbandingan rata-rata perkembangan motorik halus pada anak sebelum dan sesudah diberikan finger painting, pada kelompok eksperimen.

Tabel. 2 Perbandingan Rata-rata perkembangan motorik halus anak sebelum dan sesudah diberikan perlakuan pada kelompok eksperimen

\begin{tabular}{lllll}
\hline Perlakuan & $\begin{array}{l}\text { Mean } \\
\text { Perkemban } \\
\text { gan }\end{array}$ & $\begin{array}{l}\text { Mean } \\
\text { Differenece }\end{array}$ & $\begin{array}{l}\boldsymbol{P} \\
\text { value }\end{array}$ & CI \\
\hline $\begin{array}{l}\text { Sebelum } \\
\text { Sesudah }\end{array}$ & 3,63 & 1,56 & 0,000 & $-2,038-(-1,087)$ \\
\hline
\end{tabular}

Tabel 2 menunjukkan bahwa setelah diberikan perlakuan, pada kelompok eksperimen mengalami peningkatan rata-rata nilai perkembangan yang bermakna sebesar 1,56 dengan $p$ value 0,000. Finger painting adalah salah satu kegiatan teknik melukis dengan mengoleskan cat pada kertas basah menggunakan jari jemari yang dapat dilakukan oleh anak untuk menuangkan imajinasi melalui lukisan yang dibuat dengan jari jemari anak(Pamadhi, 2008). Kegiatan finger painting dapat digunakan sebagai kegiatan alternatif guna menggantikan krayon agar kegiatan lebih menarik untuk anak(Maghfuroh \& Putri, n.d.).

b. Analisis perbandingan rata-rata perkembangan motorik halus pada anak sebelum dan sesudah diberikan menyusun Puzzle,pada kelompok kontrol. 
Tabel. 3 Perbandingan rata-rata perkembangan motorik halus anak sebelum dan sesudah diberikan perlakuan pada kelompok kontrol

\begin{tabular}{ccccc}
\hline Perlakuan & $\begin{array}{c}\text { Mean } \\
\text { Perkemban } \\
\text { gan }\end{array}$ & $\begin{array}{c}\text { Mean } \\
\text { Differenece }\end{array}$ & $\begin{array}{c}\boldsymbol{P} \\
\text { value }\end{array}$ & CI \\
\hline Sebelum & 3,56 & 0,56 & 0,007 & $-0,950-(-0,175)$ \\
Sesudah & 4,13 & & & \\
\hline
\end{tabular}

Tabel 3 menunjukkan bahwa setelah diberikan perlakuan, pada kelompok kontrol mengalami peningkatan rata-rata nilai perkembangan yang bermakna sebesar 0,56 dengan $p$ value 0,007 .

Menyusun puzzle adalah menyusun kembali potongan-potongan gambar yang terpisah dan tercerai berai. Potongan gambar ini memiliki berbagai bentuk(Maryunani, 2010).

c. Analisis untuk mengetahui pengaruh finger painting terhadap perkembangan motorik halus pada anak usia prasekolah di PAUD Al-Hijrah dan PAUD Smart Desa Sidoluhur Kecamatan Godean.

Tabel. 4 Perbandingan peningkatan (nilai) perkembangan motorik halus anak antar kelompok subyek

\begin{tabular}{cccccc}
\hline $\begin{array}{c}\text { Kelompok } \\
\text { Subyek }\end{array}$ & $\mathbf{N}$ & $\begin{array}{c}\text { Mean } \\
\text { peningkatan }\end{array}$ & $\begin{array}{c}\text { Mean } \\
\text { Difference }\end{array}$ & $\begin{array}{c}\boldsymbol{P} \\
\text { Value }\end{array}$ & CI (95\%) \\
\hline Intervensi & 16 & 1,56 & 1,000 & 0,002 & $4,12-1,588$ \\
Kontrol & 16 & 0,56 & & & \\
\hline
\end{tabular}

Tabel 4 menunjukkan bahwa ada pebedaan peningkatan nilai rata-rata perkembangan antara kelompok eksperimen (diberikan finger painting) dibanding dengan kelompok kontrol (menyusun Puzzle) sebesar 1 p.value 0,002 CI 95\% (4,12-1,588). Dengan demikian dapat disimpulkan bahwa ada pengaruh finger painting terhadap perkembangan motorik halus pada anak prasekolah. Artinya finger painting lebih efektif dibanding menyusun Puzzle dalam menstimulasi perkembangan motorik halus pada anak prasekolah.

Menurut Soetjiningsih, 1995 secara umum terdapat dua faktor utama yang mempengaruhi tumbuh kembang anak, yaitu faktor internal dan faktor eksternal. Faktor internal merupakan modal dasar dalam mencapai hasil akhir tumbuh kembang anak, sedangkan faktor eksternal sangat menentukan tercapai atau tidaknya potensi bawaan(Soetjiningsih, 2013). Perkembangan (Development) adalah bertambahnya kemampuan (skill) dalam struktur dan fungsi yang lebih kompleks dalam pola yang teratur dan dapat diramalkan, sebagai hasil dari proses pematangan. Perkembangan menyangkut adanya proses diferensiasi dari sel-sel tubuh, jaringan tubuh, organ-organ dan sistem organ untuk dapat memenuhi fungsinya masing-masing.

Perkembangan motorik halus (fine motor development) merupakan aspek yang berhubungan dengan kemampuan anak melakukan gerakan yang melibatkan bagian-bagian tubuh tertentu dan dilakukan oleh otot-otot kecil seperti menjimpit, menulis(Soetjiningsih, 2013), memegang mainan, menggunakan sendok, mengancingkan baju atau meraih sesuatu yang memerlukan ketangkasan jari(John W. Santrock, 2011). Pengembangan motorik halus dapat menjadi dasar bagi anak belajar menulis. Pada prinsipnya belajar menulis dapat dilakukan apabila otot-otot halus anak sudah siap, dan kelenturan jari-jari tangan. 
Pada penelitian ini, faktor yang diteliti adalah faktor eksternal khususnya Stimulasi. Stimulasi merupakan perangsangan yang datang dari lingkungan luar anak yang sangat penting untuk tumbuh kembang anak. Penelitian ini berfokus pada 2 jenis stimulasi untuk mengembangkan perkembangan motorik halus anak yaitu stimulasi menggunakan finger painting dan menyusun puzzle.

Penelitian ini melibatkan 32 orang anak yang termasuk dalam kriteria inklusi dan eksklusi dengan proporsi subyek yang berjenis kelamin laki-laki pada kelompok eksperimen tidak berbeda bermakna dibanding dengan kelompok kontrol $(56,25 \%$ vs 56,25\%) $p$ value 1,000 ; proporsi ibu subyek yang berpendidikan dasar pada kelompok eksperimen juga tidak berbeda bermakna dibanding dengan kelompok kontrol (25\% vs $18,75 \%) p$ value 0,453 . Proporsi ayah subyek yang berpendidikan dasar pada kelompok eksperimen juga tidak berbeda bermakna dengan kelompok kontrol $(31,25 \%$ vs $25 \%)$, $p$ value 0,645 . Demikian pula proporsi orang tua (keluarga) dari subyek yang berpenghasilan kurang dari Rp.1.701.000,- (UMR) pada kelompok eksperimen tidak berbeda bermakna dibanding dengan kelompok kontrol $(37,50 \%$ vs $37,50 \%) p$ value 1,000 . Jadi, beberapa perbedaan proporsi tersebut tidak bermakna secara statistik dan dengan demikian karakteristikkarakteristik tersebut tidak mengganggu atau tidak mempengaruhi perbedaan peningkatan perkembangan motorik halus antar kedua kelompok subyek.

Setiap anak mampu mencapai perkembangan motorik halus yang optimal, asalkan mendapat stimulasi yang tepat. Banyak konsep dan fakta yang ditemukan memberikan penjelasan periode keemasan pada anak usia dini. Dimana semua potensi anak berkembang paling cepat. Konsep tersebut diperkuat oleh fakta yang ditemukan oleh para ahli neurologi yang menyatakan bahwa pada saat lahir otak bayi mengandung 100 sampai 200 miliar neuron atau sel saraf yang siap melakukan sambungan antar sel. Sekitar 50\% kapasitas kecerdasan manusia telah terjadi ketika usia 4 tahun, $80 \%$ telah terjadi ketika anak berusia 8 hingga 18 tahun(Maryani, 2018).

Pada penelitian ini menurut hasil uji Paired T-Test dengan software komputer didapatkan perkembangan motorik halus anak sesudah diberi perlakuan baik kelompok eksperimen ( $p$ value $0,000)$ maupun kelompok kontrol ( $p$ value 0,007 ) mengalami peningkatan yaitu pada kelompok eksperimen rerata sebelum diberikan finger painting sebesar 3,63; sesudah diberi finger painting menjadi 5,19 dan pada kelompok kontrol rerata sebelum diberikan menyusun puzzle sebesar 3,56; sesudah diberi menyusun puzzle menjadi 4,13 . Hal ini sesuai dengan teori yang menyebutkan bahwa Kegiatan pembelajaran untuk mengembangkan motorik halus dapat dilakukan dengan alatalat permainan indoor, seperti memasang puzzle, menyusun balok, memasukan kotak pos, merangkai logo, kegiatan finger painting, membuat kolase, mozaik, memilin dan memeras koran, menempel dan lain sebagainya(Maryunani, 2010).

Finger painting adalah salah satu kegiatan teknik melukis dengan mengoleskan cat pada kertas basah menggunakan jari jemari yang dapat dilakukan oleh anak untuk menuangkan imajinasi melalui lukisan yang dibuat dengan jari jemari anak(Pamadhi, 2008). Kegiatan finger painting dapat digunakan sebagai kegiatan alternatif guna menggantikan krayon agar kegiatan lebih menarik untuk anak(Maghfuroh \& Putri, n.d.). Sedangkan menyusun puzzle adalah menyusun kembali potongan-potongan gambar yang terpisah dan tercerai berai. Potongan gambar ini memiliki berbagai bentuk. Kedua jenis stimulasi ini meningkatkanan perkembangan motorik halus pada anak.

Meskipun demikian perkembangan motorik halus anak pada kedua kelompok mengalami perbedaan peningkatan rerata. Menurut hasil uji bivariat yang dilakukan dengan Independent $T$ Test dengan software komputer didapatkan perbedaan peningkatan rata-rata nilai perkembangan antar kelompok subyek sebesar 1,000 dengan p-value 0,002 <0,05. Dari nilai tersebut dapat disimpulkan bahwa terdapat perbedaan bermakna peningkatan rata-rata nilai perkembangan 
motorik halus antara kelompok eksperimen dan kelompok kontrol. Pemberian intervensi pada kelompok eksperimen lebih berpengaruh dalam meningkatkan perkembangan motorik halus anak usia prasekolah daripada pemberian intervensi yang diberikan pada kelompok kontrol.

Kriteria inklusi yang digunakan dalam menentukan subyek penelitian ini adalah Orangtua/wali bersedia anaknya menjadi subyek penelitian, anak berusia $>2$ tahun $-\leq 4$ Tahun dan kriteria eksklusi dalam menentukan subyek penelitian ini adalah Anak tidak mau dilakukan pemeriksaan DDST II, dan Sakit/ malu melakukan pemeriksaan DDST II.

Hasil Penelitian lain yang dilakukan Lilis Maghfiroh dkk (2017) yang menyatakan ada pengaruh finger painting terhadap perkembangan motorik halus anak di TK Sartika 1 Sumurgenuk, Kecamatan Babat, Lamongan(Maghfuroh \& Putri, n.d.) dan juga sejalan dengan penelitian yang dilakukan oleh Suryaningsih Nurjanah dkk (2017) yang menyatakan ada perbedaan yang signifkan perkembangan motorik halus sebelum dan sesudah diberikan finger painting di TK At-Taqwa(Sari, Nur, \& Purwanto, 2012). Keberhasilan dalam penelitian tersebut menunjukkan bahwa penerapan kegiatan finger painting lebih meningkatkan kemampuan motorik halus anak.

Namun penelitian lain menunjukkan bahwa finger painting tidak berpengaruh besar dalam perkembangan motorik anak. Hal tersebut diungkapkan oleh Tri Maryani dkk (2018) dalam penelitiannya yang berjudul pengaruh stimulasi perkembangan dengan teknik finger painting terhadap kemampuan motorik dan frekuensi tantrum anak usia toddler. Pada penelitian tersebut disebutkan sebelum dan sesudah diberi finger painting lebih berpengaruh terhadap frekuensi tantrum daripada perkembangan motorik anak. Semua anak dapat melakukan tugas perkembangan pada aspek motoriknya sedangkan frekuensi tantrum mengalami penurunan perilaku setelah diberikan finger painting. Instrumen yang digunakan pada penelitian tersebut adalah form (Kuesioner Pra Skrining Perkembangan) KPSP dengan menggunakan interpretasi normal dan penyimpangan(Maryani, 2018).

Meskipun demikian, dalam penelitian Tri Maryani dkk (2018) tidak dilihat peningkatan rerata perkembangan motorik pada anak, hanya dilihat anak tersebut mendapat interpretasi normal atau penyimpangan. Sedangan dalam penelitian ini instrumen yang digunakan adalah DDST II dengan interpretasi berupa angka, jadi dalam penelitian ini dapat dilihat peningkatan perkembangan antara pemberian finger painting dan menyusun puzzle secara numerik dan lebih detail.

Pada penelitian ini anak diberikan perlakuan sekitar 30 menit dengan interval 2 hari sekali baik pada kelompok eksperimen maupun kelompok kontrol. Dengan harapan anak tidak bosan dan mendapatkan perlakuan yang sama dalam meningkatkan perkembangan motorik halus, namun dengan jenis stimulasi yang berbeda. Gangguan perkembangan yang dialami pada anak dapat berdampak buruk untuk masa depan anak. Anak yang mengalami gangguan motorik dapat terlambat memperoleh keterampilan yang seharusnya dapat dicapai sesuai usianya. Karakteristik anak dengan kecerdasan motorik halus baik adalah mudah dan lebih baik dalam melakukan beberapa aktivitas seperti memakai baju, menggunting, menggambar, dan menulis. Sedangkan dampak yang disebabkan oleh keterlambatan motorik halus adalah kesulitan anak dalam aktivitas seperti yang dijelaskan pada karakteristik anak dengan kemampuan motorik halus yang baik(Fida \& Maya, 2012).

\section{KESIMPULAN}

Berdasarkan uraian diatas dapat disimpulkan bahwa ada pengaruh finger painting terhadap perkembangan motorik halus anak usia prasekolah di PAUD Al-Hijrah dan PAUD Smart Desa Sidoluhur Kecamatan Godean Kabupaten Sleman. Finger panting lebih efektif dibanding menyusun puzzle dalam mentimulasi perkembangan motorik halus pada anak prasekolah. 
Meskipun Finger panting dan menyusun puzzle, kedua-duanya mampu meningkatkan perkembangan motorik halus pada anak prasekolah secara bermakna. Secara garis besar disarankan untuk menggunakan finger painting dalam melakukan stimulasi tumbuh kembang terutama perkembangan motorik halus anak, bagi orangtua dapat memberikan stimulasi finger painting ini dirumah agar perkembangan motorik halus anak semakin meningkat, dan Peneliti selanjutnya disarankan dapat mengembangkan penelitian dengan membandingkan alat permaianan lainnya untuk meningkatkan perkembangan motorik halus anak.

\section{UCAPAN TERIMA KASIH}

Bapak Joko Susilo, SKM.,MS. selaku Direktur Poltekkes Kemenkes Yogyakarta, Ibu DR. Yuni Kusmiyati, SST.,MPH. selaku Ketua Jurusan Kebidanan Poltekkes Kemenkes Yogyakarta, Ibu Yuliasti Eka Purnamaningrum, SST.,MPH. selaku Ketua Prodi Sarjana Terapan Poltekkes Kemenkes Yogyakarta, Ibu Hesty Widyasih S.SiT.,M.Keb. selaku Pembimbing Utama, Bapak Margono S.Pd.,APP.,M.Sc selaku Pembimbing Pendamping, Ibu Munica Rita Hernayanti SST, M.Kes selaku penguji skripsi, Ibu Is Rahayu A.Md Keb selaku Kepala Sekolah PAUD Al-Hijrah, Ibu Suharwatini S.E selaku Kepala Sekolah PAUD Smart, Ayahanda Karso Widodo dan Ibunda Rosidah selaku kedua orang tua serta adik tercinta Istna Kafa Chaerunnisa.

\section{DAFTAR PUSTAKA}

Aquarisnawati, P., Mustami'ah, D., \& Riskasari, W. (2011). Motorik Halus pada Anak Usia Prasekolah Ditinjau dari Bender Gestalt. Jurnal Insan, 13, 149-156.

Fida, \& Maya. (2012). Pengantar Ilmu Kesehatan Anak. Yogyakarta: D-Medika.

Hurlock, E. (2013). Perkembangan Anak. ERLANGGA.

John W. Santrock. (2011). Masa Perkembangan Anak. (V. Pakpahan, Ed.) (11th ed.). Jakarta: Salemba Medika.

Kemenkes, R. (2017). Laporan Tahunan. In Buletin Jendela Data dan Informasi Kesehatan (pp. 29-33).

Maghfuroh, L., \& Putri, K. C. (n.d.). The Effect Of Finger painting To The Development Of Fine Motor On Preschool Children In Sartika I Sumurgenuk Kindergarten Babat Lamongan Penelitian yang dilakukan oleh Partiyem , 2014 pada kelompok B PAUD Istiqomah di Sumber Bening Kecamatan Selupu Rejang.

Maryani, T. (2018). Dwiana Estiwidani, SST, MPH (Vol. 372).

Maryunani, A. (2010). Ilmu Kesehatan Anak dal Kebidanan. Jakarta: Trans Info Media.

Notoatmodjo, S. (2012). Metodologi Penelitian Kesehatan (Revisi Cet). Jakarta: Rineka Cipta.

Pamadhi. (2008). Seni Ketrampilan Anak. Jakarta: Universitas Terbuka.

Puskemas Godean I. (2018). Register DTKB Puskesmas Godean I. Yogyakarta: puskesmas Godean.

RI, K. K. (2018). Hasil Utama Riskesdas 2018. Jakarta: Kementrian Kesehatan RI.

Sari, D. W., Nur, E., \& Purwanto, S. (2012). Hubungan Antara Status Gizi Dengan Perkembangan. Jurnal Kesehatan, 5(1979-7621), 157-164.

Soetjiningsih. (2013). Tumbuh Kembang Anak (2nd ed.). Jakarta: EGC.

Sulistyawati, A. (2014). Deteksi Tumbuh Kembang Anak. Jakarta: Salemba Medika.

Wayan, N., Asthiningsih, W., \& Muflihatin, S. K. (2018). Deteksi Dini Perkembangan Anak dengan Metode, 3(2), 367-374. 